\title{
Smart Hot Chamber in Refrigeration System Based on Waste Heat Recovery
}

\author{
V. Naveenprabhu*, F. Justin Dhiraviam, K.M. Gowtham, S. Gowtham, R. Afsal Tharick and \\ R. Arunkumar \\ Department of Mechanical Engineering, Sri Eshwar College of Engineering, Kondampatti - 641202, Tamil Nadu, \\ India; naveenprabhu.v@sece.ac.in, justin.f@sece.ac.in, gouthamkm4897@gmail.com,gowtham.xxx22@gmail.com, \\ afsaltharick19@gmail.com, arunkumartrkpm@gmail.co
}

\begin{abstract}
Objective: Nowadays, the refrigeration system is commonly used in most places viz. bakery shops, hotels and other food processing industries, where food items are refrigerated to preserve and, subsequently heated before consumption. In order to eliminate the dual energy consumption devices separately our idea is to do heating and cooling with the single refrigeration unit. Methods/Findings: The idea is to improve the recovery of the waste heat generated in the refrigeration unit. The heat is generally dumped to the atmosphere through the condenser. This heat is utilized to maintain the chamber situated at the topmost of the refrigerator unit as hot chamber. Application: The waste heat that recovered will be an energy saving smart approach and also implies reduction in the green-house gas emission to the environment.
\end{abstract}

Keywords: Capillary Tube, Compressed Refrigerant, Condenser Coil, Evaporator Coil, Heating Coil, Preservation

\section{Introduction}

The refrigeration system means to keep the system at a lesser temperature than its environments. Essentially, the transfer of heat occurs in only one direction which is from the hot region to the cool region. This is achieved in a closed space by using the refrigeration cycle. A refrigeration cycle is generally a heat pump but works in a way exactly opposite to it as heat pump heats the system while the refrigeration cycle chills the system. Refrigeration cycle practices refrigerants as the heat transfer medium. Refrigerants are chemical compositions that are alternately compressed and condensed into a liquid and then permitted to expand into a vapour or gas as they are pumped through the mechanical refrigeration system to cycle. The most commonly used refrigerant is R134a. It comes in all shapes and sizes suiting the need of different areas like hospital, market and homes.

This device plays a vital role in human life by preserving food and many other materials. This device also plays a very important role in the medical field and scientific researches.

To minimize the energy consumption a lot of methods are used for the improvement of the Coefficient Of Performance (COP) of the system. But it needs specialized care about the consuming equipment and frequent time and money consuming maintenance are required. In order to overcome this practical difficulty combined cycle working is one of the efficient methods of reducing energy consumption as the whole usage. Normally waste heat recovery is done on the waste heat removal through fluids such as water, air or other heat conducting fluids. These kinds of fluids are heated and done the job after that the heat is dumped into the environment through the condenser or cooling tower like equipment. Always cooling equipment generates a large amount of heat. If it is not utilized the energy becomes simply waste energy, that kind of energy is our main aim of using into useful manner.

${ }^{*}$ Author for correspondence 


\section{Literature Survey}

$\mathrm{In}^{1}$ studied and developed a modern heat regenerative adsorption refrigerator where he used a spiral plate heat exchangers as absorbers and an adsorption heat pump. For air conditioning using plate-fin heat exchangers or plate fin shell and tube type heat exchangers as absorbers. Activated carbon and methanol adsorption pair are used for the two kinds of adsorption systems. With a heat source temperature of $100^{\circ} \mathrm{C}$, the refrigerator achieved a refrigeration power density of more than $2.6 \mathrm{~kg}$ ice per day per $\mathrm{kg}$ activated carbon where the $\mathrm{COP}$ is 0.13 , and the heat pump achieved $150 \mathrm{~W} / \mathrm{kg}$ galvanized carbons for air conditioning with a COP of about 0.4 . The heat exchanger was initially proposed and conduction mode is finalized.

$\mathrm{In}^{2}$ has done research on energy conservation which involves turning excess or waste heat into electricity. This was initially considered to be our main focus, but our work doesn't generate enough heat for a decent electricity generation. The Thermoelectric material is a solid-state energy converter which is a combination of thermal, electrical and semiconducting properties to convert waste heat into electricity or electrical power directly into cooling and heating. These materials can be competitive with fluid-based systems, such as two-phase air-conditioning compressors or heat pumps, or used in smaller-scale applications such as in automobile seats, night-vision systems, and electrical-enclosure cooling. More use of thermoelectric materials requires both the fundamental energy conversion effectiveness of the materials and implementing recent advancements in system architecture. This way of utilizing heat to produce electricity was also considered and is decided to include in forthcoming once.

In ${ }^{\underline{3}}$ worked on heat activated cooling has the potential of utilizing thermal sources that currently go unused such as engine exhaust heat or industrial waste heat. Using these heat sources can provide enhanced energy utilization and reduced fuel usage in applications where cooling is needed. The concept developed here uses waste heat from stationary and mobile engine cycles to generate cooling for structures and vehicles. It syndicates a biological Rankine cycle with a conventional vapour compression cycle.

A nominal $5 \mathrm{~kW}$ cooling capacity prototype system was developed based on this concept and it was tested under laboratory conditions, in order to maintain high system performance when size and weight for portable applications are reduced.
$\mathrm{In}^{4}$ worked on a latent heat thermal energy storage system can be castoff to recover the waste heat which is produced by the refrigerant by means of excess compressing of refrigerant in air conditioning systems, which will be enough energy to produce hot water from cold water. Its reductions, not only for the consumption of electrical energy consumption for heating domestic hot water but also the calefaction to the surroundings due to the rejection of heat from air conditioning systems. A retrieval arrangement that uses a Phase Change Materials (PCMs) to store the rejected (sensible and condensation) heat from air condition system has been developed and studied, making up the shortage of other sensible heat storage system. But in our case, latent heat is neglected as the system will become too complex to analyze.

$\mathrm{In}^{\underline{5}}$ did investigation of two-phase stream mechanisms during condensation of refrigerant R134a in six small diameters round $(4.91 \mathrm{~mm})$, square $(\mathrm{Dh}=4 \mathrm{~mm}, \alpha=1)$, and rectangular $(4 \times 6 \mathrm{~mm}$ and $6 \times 4 \mathrm{~mm})$ was showed. Unique investigational methods and valuation sections were established to enable the documentation of the stream mechanisms during phase change.

$\mathrm{In}^{6}$ had conducted experiments on heat pipe cooled air conditioner. Due to the effective mean of heat transfer and increase the heat transfer rate at the evaporator the total effectiveness of the setup will increase up to $85 \%$.

$\mathrm{In}^{7.8}$ explains the performance of nano fluid in the heat exchanger especially in the tube in tube type. $\mathrm{Al} 2 \mathrm{O} 3$ is one of the aluminium oxide nano particles. It is used for nano fluid preparation through the ultrasonication process. The synthesized nano fluids are used in the cold fluid side in the tube in tube heat exchanger. In hot fluid side, normal water is used, when we use the nano fluids in hotter side fluid it reacts with exchanger material to corrode or the formation of heterogeneous chemical slag on the walls of the inside of the heat exchanger. The system is tested with the normal hot water as hot fluid and synthesized nano fluid as used as the cold fluid and the result shows that sage of nano fluid increases the effectiveness by $60 \%$ and heat transfer rate by $42 \%$.

$\mathrm{In}^{2}$ did research on aluminium foil as an insulator. The principle involved in all uses of aluminium for insulation is the reflection of radiant heat. Still, air offers a higher resistance to the transmission of heat by conduction than any available insulating material, but heat is readily transferred through the air by radiation and convection. Convection may be minimized by subdividing an air space into small cells, and radiation reduced by bounding 
the air cells with a material of low thermal emissivity such as aluminium foil. This material may be applied to structural materials or used to subdivide an air space.

In ${ }^{10-11}$ has conducted experiments on the automobile cooling system in the intercooler as well as in the solar vehicle. The effective result showcased that reposition of the heat transfer surface in either of the vehicle gives that the increase in heat transfer rate.

$\mathrm{In}^{12}$ and ${ }^{13}$ showcases their result on the brazen type plate heat exchanger and proved the result that the heat transfer rate of plate heat exchanger is high enough when compared to the all other type of the heat exchanger.

\section{Experimental Setup}

Figure 1 shows the experimental setup of the waste heat retrieval system for the hot preservation process. In a normal refrigeration system, the refrigerant fluid which is compressed in compressor possesses excess temperature and pressure than the standard requirements. The normal systems having two heat carrying devices condenser and evaporator. The evaporator is used to cool the surroundings and condenser is to release the compressed refrigerant heat. The inlet to obtainable temperature variance in the condenser is about $40^{\circ} \mathrm{C}$ to $60^{\circ} \mathrm{C}$, higher the difference higher the performance of the system. The expansion valve is used to expand the low-pressure lowtemperature vapour into low-temperature liquid and that liquid is passed into the evaporator.

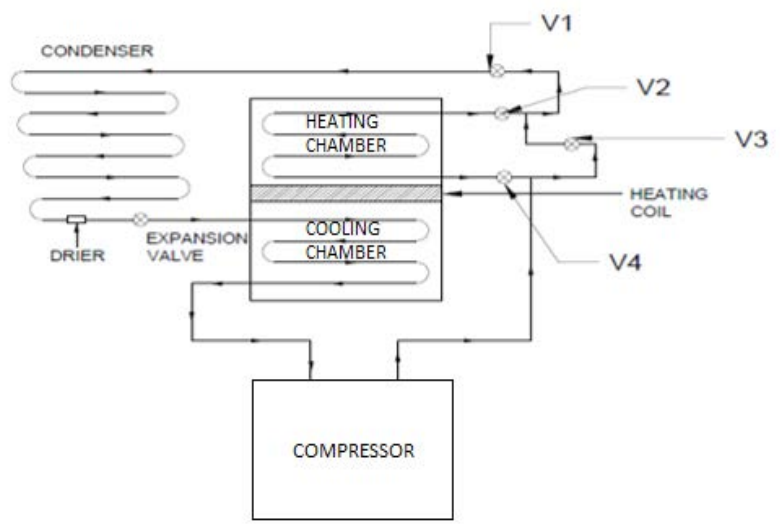

Figure 1. Experimental arrangement of excess temperature retrieval structure.

In waste heat system compressed a fluid, which is having the high temperature is bypassed by the set off valves and directed towards the heating chamber which is made up of copper pipes and copper plates is indicates in Figure 2 , for the most efficient heat transfer from the hot refrigerant to the hot chamber. Due to heat transfer in the hot chamber, the refrigerant fluid is losses its temperatures and permits to the expansion regulator through the condenser for the further cooling process. In this system, the temperature unconfined to the troposphere through the condenser is reduced by about $30 \%$.

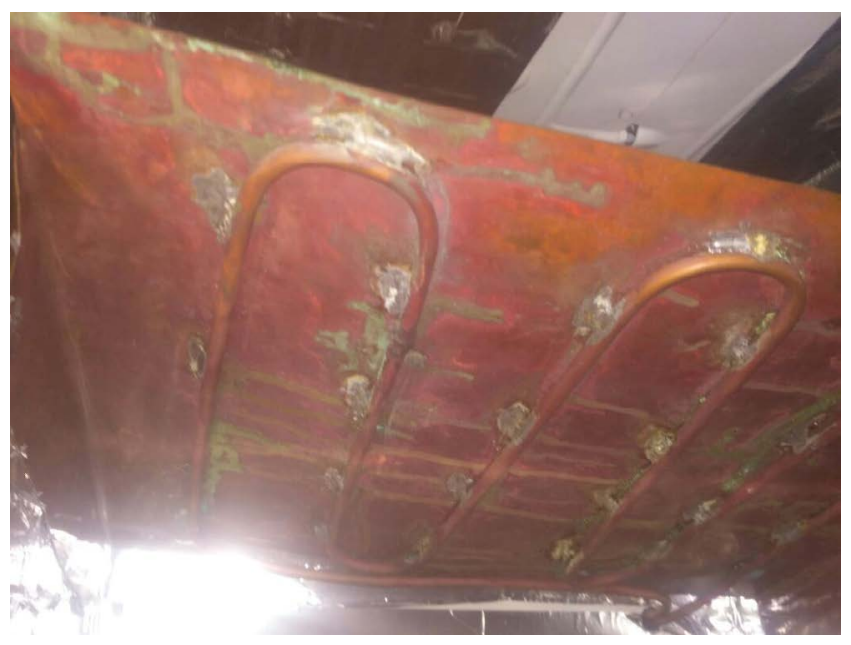

Figure 2. Heating pipe and plate arrangement in heating chamber.

In the refrigeration system refrigerant R134a, is used and the following property of the refrigerant is specified in the Table 1.

Table 1. Properties of the refrigerant R134a

\begin{tabular}{|l|l|l|}
\hline No. & Properties & R134a \\
\hline 1 & Boiling Point & $-14.9^{\circ} \mathrm{F}$ or $-26.1^{\circ} \mathrm{C}$ \\
\hline 2 & $\begin{array}{l}\text { Auto-Ignition } \\
\text { Temperature }\end{array}$ & $1418^{\circ} \mathrm{F}$ or $770^{\circ} \mathrm{C}$ \\
\hline 3 & Ozone Depletion Level & 0 \\
\hline 4 & Solubility In Water & $\begin{array}{l}0.11 \% \text { by weight at } 77^{\circ} \mathrm{F} \\
\text { or } 25^{\circ} \mathrm{C}\end{array}$ \\
\hline 5 & Critical Temperature & $252^{\circ} \mathrm{F}$ or $122^{\circ} \mathrm{C}$ \\
\hline 6 & Cylinder Color Code & Light Blue \\
\hline 7 & $\begin{array}{l}\text { Global Warming } \\
\text { Potential (GWP) }\end{array}$ & 1200 \\
\hline
\end{tabular}

\section{Result and Discussion}

Table 2 indicated the observations made from the corresponding hot and cold chambers with power consumption. 
Table 2. Observations of chamber temperature where ambient temperature $=29^{\circ} \mathrm{C}$

\begin{tabular}{|l|l|l|l|l|}
\hline $\begin{array}{l}\text { Time } \\
(\text { Min) }\end{array}$ & $\begin{array}{l}\text { Cold } \\
\text { Chamber }\left({ }^{\circ} \mathbf{C}\right)\end{array}$ & $\begin{array}{l}\text { Hot } \\
\text { Chamber } \\
\left({ }^{\circ} \mathbf{C}\right)\end{array}$ & $\begin{array}{l}\text { Power Consumed by } \\
\text { Evaporator and Hot } \\
\text { Chamber Separately }(\mathbf{K w})\end{array}$ & $\begin{array}{l}\text { Power Consumed By } \\
\text { The Heat Recovery } \\
\text { System }(\mathrm{Kw})\end{array}$ \\
\hline 10 & 15 & 38 & $\mathbf{2 8 0}$ & $\mathbf{2 2 6}$ \\
\hline 15 & 13 & 40 & 255 & 215 \\
\hline 20 & 12 & 42 & 240 & 198 \\
\hline 25 & 10 & 45 & 240 & 170 \\
\hline 30 & 7 & 46 & 235 & 156 \\
\hline 35 & 5 & 60 & 237 & 143 \\
\hline
\end{tabular}

Figure 3 shows that the temperature difference of the warm chambers and cold chambers along the time taken. It indicates that the cold chamber temperature decreases slowly and the thermostat will control the temperature maintained by the cold chamber. If the chamber reaches the ideal evaporator temperature compressor will automatically stop compressing the fluid. But the hot chamber does not control by any thermostat because the maximum temperature from the compressor is about $90^{\circ} \mathrm{C}$. So, the thermostat is not necessary for the hot chamber.

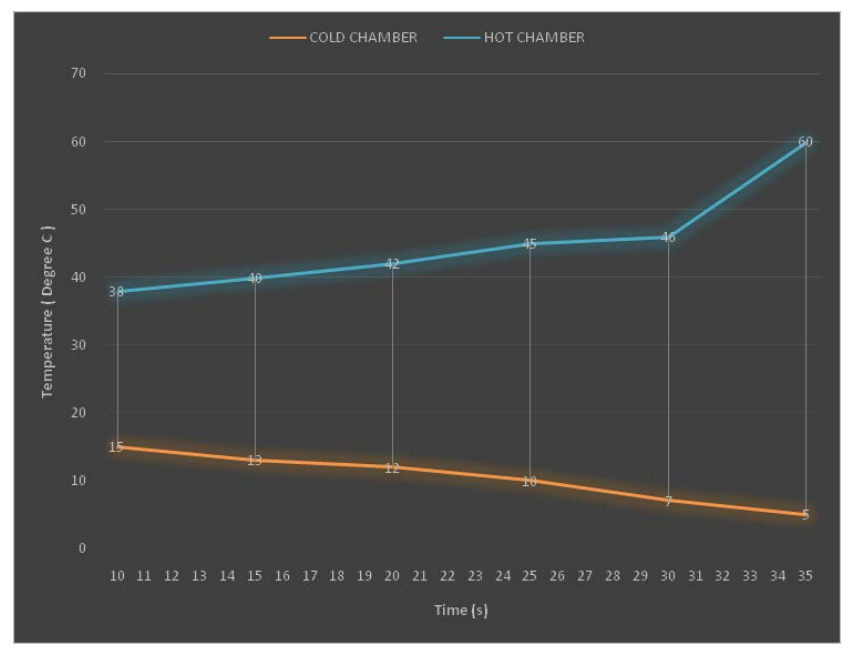

Figure 3. Time vs temperature of the chambers.

In the warm chamber, the temperature rises as the compressor are worked. The initial rise of temperature in the hot chamber is minimum. But after the cold chamber temperature drops to $7{ }^{\circ} \mathrm{C}$, the compressor needs to work more for maintaining the temperature in the cold chamber. Implies large quantity of hot refrigerant is passed through the hot chamber with a short period of time. As a result of that temperature in the hot chamber will drastically increase. Figure 4 indicates that the power consumption of compressor for the running time. The power consumption indicated for the ideal equipment is the summation of the refrigerator and heater separately consumed power for the same capacity. The power consumed by the compressor during the heat recovery system operated condition is reducing compared to the total power consumption of the refrigerator and heater. But when compared with the ideal refrigeration system alone the power consumption is increases by about $23 \%$.

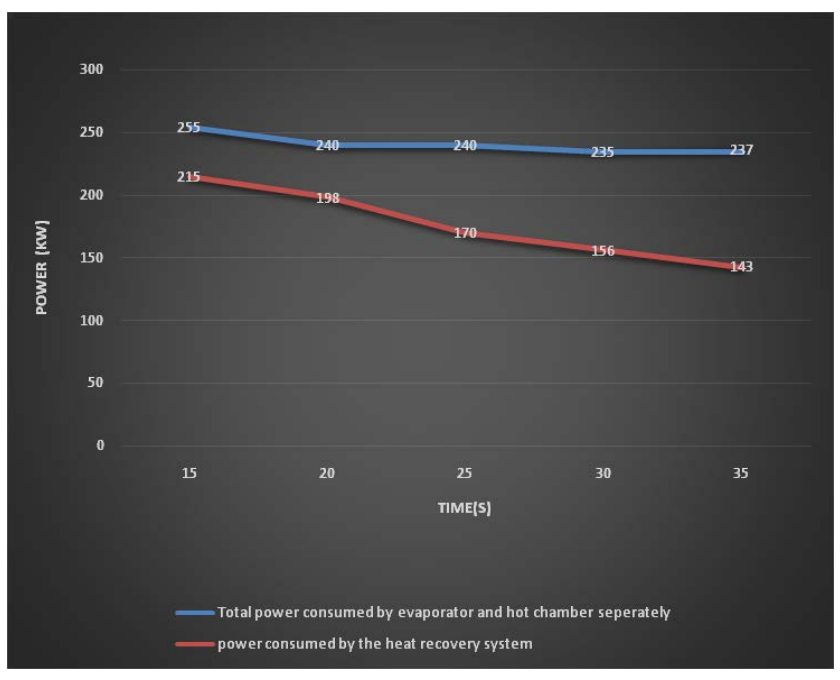

Figure 4. Time vs power consumption.

\section{Conclusion}

The energy consumption of the refrigeration and the heater combined setup will reduce the energy consumption by $40 \%$. As well as COP of the system will not affect from the original condition. But it may increase the performance of the evaporator system by increasing the heat transfer from the condenser or by supply the lower temperature refrigerant to the expansion valve. 
Our project enables us to do both heating and cooling in same setup to achieve a hybrid system. The eventual aim of our project is to reduce the consumption of electricity in the domestic level usage and to produce heating and cooling in the same setup. The goal is achieved and by that heating is also obtained in a separate chamber. Our project is cost effective and can be used everywhere to reduce power consumption as the heating chamber solely works on the excess heat otherwise left out to outer atmosphere. We would like to concentrate on refrigerant properties, compressor and so on to raise the effectiveness of the system.

\section{References}

1. Wang RZ, Wu JY, Xu YX, Teng Y, Shi W. Spiral plate heat exchanger, Energy Conversion and Management. 2001; 42(2):13-23.

2. Bell LE. Electricity production by heat recovery in air conditioning and refrigeration, Science. 2008; 4(6):145-46.

3. Gu Z, Liu HJ, Li Y. Heat recovery system for air conditioner, Applied Thermal Engineering. 2004; 24(17-18):2511-26. https://doi.org/10.1016/j.applthermaleng.2004.03.017.

4. Wang H. Performance of a combined organic Rankine cycle and vapor compression cycle for heat activated cooling, Energy. 2011; 36(1):447-58. https://doi.org/10.1016/j. energy.2010.10.020.

5. Coleman JW, Garimella S. Two-phase flow regimes in round, square and rectangular tubes during condensation of refrigerant R134a, International Journal of Refrigeration. 2003; 26(1):117-28. https://doi.org/10.1016/S01407007(02)00013-0.
6. Abd El-Baky MA. Heat pipe heat exchanger for heat recovery in air conditioning, Applied Thermal Engineering. 2007; 27(4):795-801. https://doi.org/10.1016/j.applthermaleng.2006.10.020.

7. Naveenprabhu V, Suresh M. Performance evaluation of tube-in-tube heat exchanger using nano fluids, Applied Mechanics and Materials. 2015; 787:72-76. https://doi. org/10.4028/www.scientific.net/AMM.787.72.

8. Naveen Prabhu V, Saravana Kumar K, Suresh T, Suresh M. Experimental investigation on tube-in-tube heat exchanger using nano fluids, Advances in Natural and Applied Sciences. 2016; 10(7):272-78.

9. Callender. Aluminium Foil for Insulation, Architectural Forum. 2014; 60(2):67-71.

10. Justin Dhiraviam F, Naveen Prabhu V, Suresh T, Selva Senthil Prabhu C. Improved efficiency in engine cooling system by repositioning of turbo inter cooler, Applied Mechanics and Materials. 2015; 787:792-96. https://doi. org/10.4028/www.scientific.net/AMM.787.792.

11. Naveen Prabhu V, Manigandan N. Design and Fabrication of Solar Transport Vehicle, IOSR Journal of Mechanical and Civil Engineering. 2016; 14-19.

12. Manigandan $\mathrm{N}$, Naveenprabhu $\mathrm{V}$, Devakumar $\mathrm{M}$. Design and fabrication of mechanical device for effective degreasing in roller bearing, Science Direct-Procedia Engineering. 2014; 97:134-40. https://doi.org/10.1016/j. proeng.2014.12.234.

13. Manigandan N, Naveen Prabhu V, Suresh M. Experimental investigation of a brazed chevron type plate heat exchanger, International Journal of Science Technology and Engineering. 2015; 1(12):1-7. 